\title{
Spatial patterns of biphasic ectoenzymatic kinetics related to biogeochemical properties in the Mediterranean Sea.
}

France Van Wambeke ${ }^{1}$, Elvira Pulido ${ }^{1}$, Julie Dinasquet ${ }^{2,3}$, Kahina Djaoudi ${ }^{1,4}$, Anja Engel ${ }^{5}$, Marc Garel $^{1}$, Sophie Guasco ${ }^{1}$, Sandra Nunige ${ }^{1}$, Vincent Taillandier ${ }^{6}$, Birthe Zäncker ${ }^{6,7}$, Christian

5 Tamburini ${ }^{1}$.

\section{Supplementary Material}

Figure S1. a) Distribution of total aminoacids (TAA, bars, lef scale) and TAA-N/DON ratio (dots, 10 right scale). b) Distribution of total combined carbohydrates (TCHO, bars, left scale) and TCHOC/DOC ratio (dots, right scale). At each station four data are presented, corresponding to, from left to right, 'surf', 'dcm', 'liw' and 'mdw' layers, respectively. At stations ST10, ST1 and ST2, DON data at 'mdw' and 'liw' layers were not available

15 Figure S2. Distribution of bacterial production (BP, a) and bacterial abundances (BA, b). At each station four data are presented, corresponding to, from left to right, 'surf', 'dcm', 'liw' and 'mdw' layers, respectively. BP data are not available for 'liw' layer at stations ST2 and ST4, and 'mdw' layer at station FAST, ST2, ST4, ST6. 

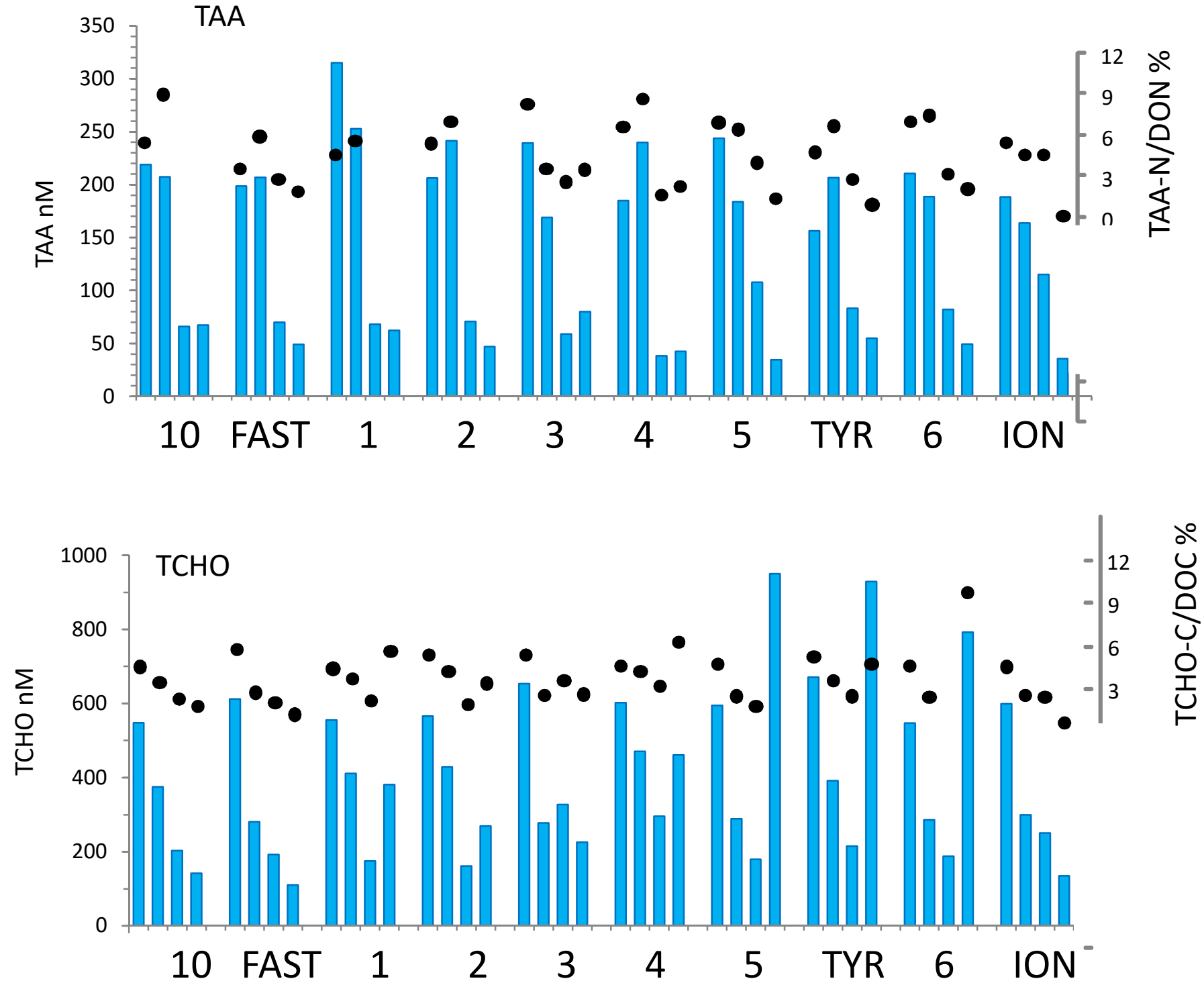

Fig S1 

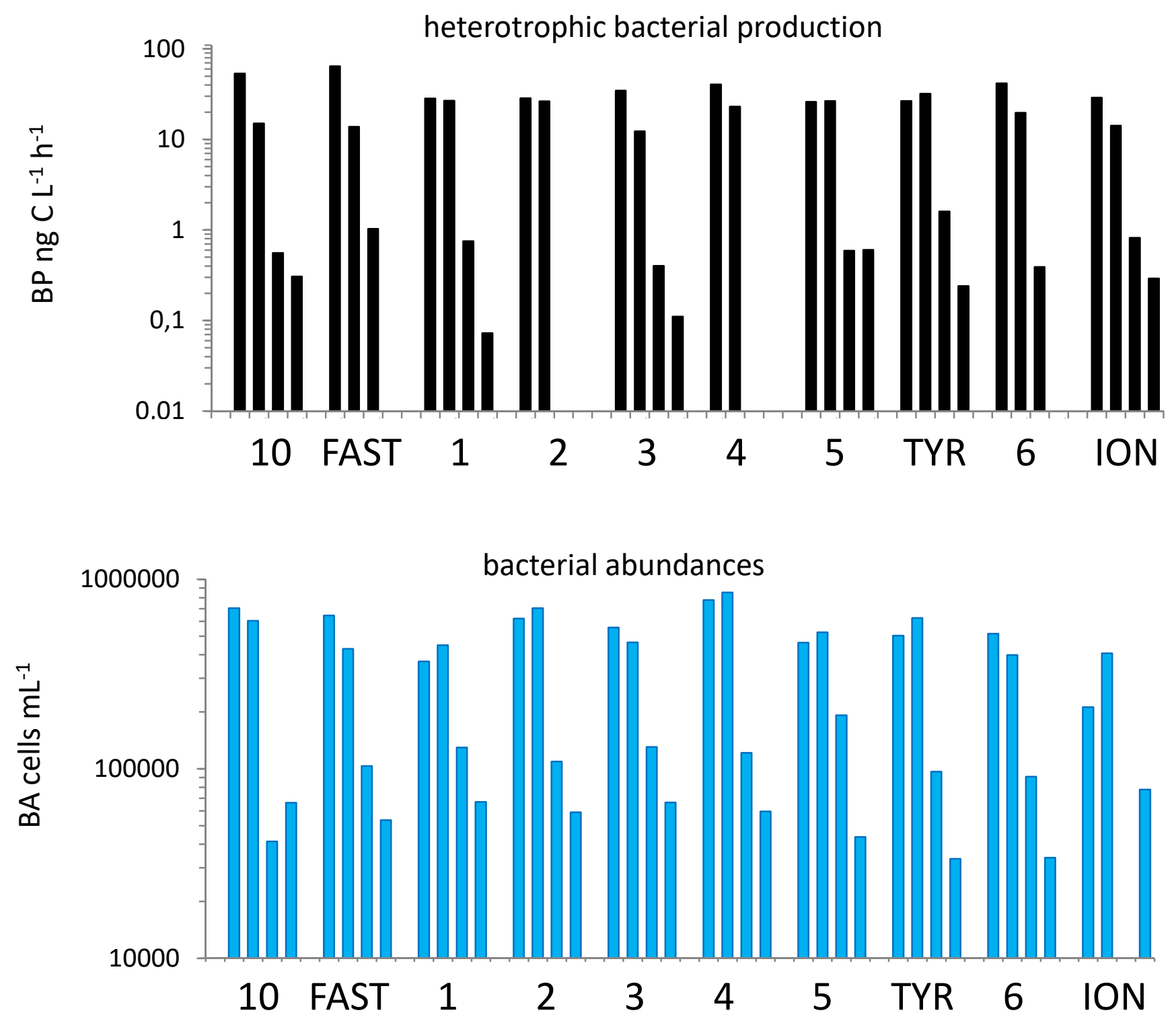

Fig S2 
Table S1. Average standard deviations and ranges of biogeochemical parameters, nitrates (NO3), nitrites (NO2), dissolved inorganic phosphate (DIP), total chlorophyll a (TChl a), dissolved organic carbon (DOC), dissolved organic nitrogen (DON), dissolved organic phosphorus (DOP), total combined amino acids (TAA), total combined carbohydrates (TCHO), at the four layers sampled.*LWCC technique, ** classical method

\begin{tabular}{|c|c|c|c|c|c|}
\hline & & surface & $\mathrm{dcm}$ & liwlayers & mdw waters \\
\hline NO3 & mean $\pm \mathrm{sd}$ & $0.013 \pm 0.018$ & $0.88 \pm 0.59$ & $7.38 \pm 2.57$ & $8.29 \pm 1.30$ \\
\hline$\mu \mathrm{M}$ & range & $\mathrm{ld}-0.056$ & $0.27-1.75$ & $2.5-9.7$ & $4.94-9.15$ \\
\hline $\mathrm{NO} 2$ & mean $\pm \mathrm{sd}$ & ld & $106 \pm 76$ & $10 \pm 4$ & ld \\
\hline $\mathrm{nM}$ & range & ld & $1 d-216$ & ld -15 & ld \\
\hline DIP & mean $\pm \mathrm{sd}$ & $10 \pm 4 *$ & $35 \pm 30 *$ & $0.29 \pm 0.13 * *$ & $0.36 \pm 0.07 * *$ \\
\hline $\mathrm{nM}^{*}, \mu \mathrm{M}^{* *}$ & range & $4-17$ & $9-107$ & $0.05-0.43$ & $0.17-0.41$ \\
\hline TChl a & mean $\pm \mathrm{sd}$ & $0.08 \pm 0.04$ & $0.54 \pm 0.15$ & nd & nd \\
\hline$\mu \mathrm{g} \mathrm{l}^{-1}$ & range & $0.06-0.19$ & $0.31-0.82$ & & \\
\hline DOC & mean $\pm \mathrm{sd}$ & $71 \pm 4$ & $62 \pm 3$ & $51 \pm 4$ & $45 \pm 3$ \\
\hline$\mu \mathrm{M}$ & range & $60-75$ & $58-66$ & $45-58$ & $39-49$ \\
\hline DON & mean $\pm \mathrm{sd}$ & $5.7 \pm 1.8$ & $5.1 \pm 1.2$ & $3.6 \pm 0.3$ & $3.2 \pm 0.4$ \\
\hline$\mu \mathrm{M}$ & range & $4.4-10.4$ & $3.5-7.4$ & $3.1-4.0$ & $2.5-3.4$ \\
\hline DOP & mean $\pm \mathrm{sd}$ & $0.05 \pm 0.03$ & $0.05 \pm 0.04$ & $0.04 \pm 0.01$ & $0.04 \pm 0.01$ \\
\hline$\mu \mathrm{M}$ & range & $0.01-0.09$ & $\mathrm{ld}-0.12$ & $0.02-0.05$ & $0.03-0.05$ \\
\hline TAA & mean $\pm \mathrm{sd}$ & $216 \pm 43$ & $206 \pm 31$ & $76 \pm 23$ & $52 \pm 14$ \\
\hline $\mathrm{nM}$ & range & $156-315$ & $164-253$ & $38-115$ & $35-80$ \\
\hline TCHO & mean $\pm \mathrm{sd}$ & $595 \pm 43$ & $351 \pm 73$ & $219 \pm 55$ & $427 \pm 315$ \\
\hline $\mathrm{nM}$ & range & $547-671$ & $278-471$ & $162-328$ & $111-950$ \\
\hline
\end{tabular}

